CITATION: Rispoli, M., \& Bloom, L. (1985). Incomplete and continuing: Theoretical issues in the acquisition of tense and aspect. Journal of Child Language, 12, 471-474. Copyright: Cambridge University Press [www.cambridge.org]

\title{
Incomplete and Continuing: Theoretical Issues in the Acquisition of Tense and Aspect*
}

\author{
Matthew Rispoli and Lois Bloom \\ Teachers College, Columbia University
}

The acquisition of tense-aspect systems has been the subject of considerable research in the past several years. A major contribution to understanding this complex domain was presented in these pages by Weist, Wysocka, Witkowska-Stadnik, Buczowska \& Konieczna (1984). However, several assumptions in their presentation about child language theory and the child language literature require closer scrutiny.

Weist et al. demonstrate quite elegantly the ecological invalidity of many of the early psycholinguistic experiments that attempted to neutralize the linguistic context while eliciting one or another linguistic form, such as in the study of verb tenseaspect inflection by Bronckart \& Sinclair (1973). By neutralizing morphological priming, Bronckart \& Sinclair proposed that the child would exhibit an unprejudiced selection of tense-aspect forms. However, such unbiased selection does not occur in the real world. Weist et al. clearly demonstrate that biasing the linguistic context aids children in using temporal deictic notions appropriately, as it does in real-life situations.

This experimental success is accompanied by assumptions about the psychological nature of linguistically defined tense-aspect systems that have led them to an odd appraisal of prior research. The 'Defective Tense Hypothesis' they propose has only one logical interpretation: a cognitive structure exists but is missing some piece that will enable the structure to perform its full function. Implicit in the notion of 'defectivity' is the preformation of a cognitive structure, an issue debated between innatists and constructivists. By including Bloom, Lifter \& Hafitz (1980) among those who propose $a^{\prime}$ defectivity' argument, Weist et al. ascribe to them a preformationist attitude. However, on the contrary, Bloom et al. did not attempt any such preformationist explanation of their data, nor did they adopt a defective tense hypothesis.

*We thank Kenji Hakuta for his comments on an earlier version of this paper. Both this paper and the research referred to were supported by a research grant from The National Science Foundation, 1986-1989, to Lois Bloom. 
They attempted to show that in a language poor in overt aspect marking, English, aspectual interpretations could be made from the categories evident in child language. Further, since these categories are not overtly marked in adult morphology, and since no preformationist assumption was made, the tense categories of adult language were not at issue. The result was a set of categories driven by the data and best described as aspectual, accompanied by the claim that "Although strongly influenced at the beginning by event-aspect, children are no doubt learning tense relations at the same time; they do not learn tense only after they learn aspect" (Bloom et al. 1980: 407). Instead of proposing 'defectivity,' Bloom et al. presented a picture of a whole system, which through successive approximations would develop into an adult system.

A second point is the allusion by Weist et al. to the circularity of the analysis reported by Bloom et al. Weist et al. insist on a framework of categories independently derived prior to analysis. However, in accepting a category set based entirely on adult judgements of grammaticality, Weist et al. avoid the question of whether these categories translate into cognitive categories for the child in any revealing way. The real issue is the origin of the categories. By detouring away from the issue of cognitive origins for temporal marking systems, Weist et al. enter into a more dangerous orientation: they explain the origin of linguistic categories by assuming that they are preformed. In this view these categories exist independently and are made visible through 'objective' tests. Even these tests, however, tell us little about the universal conditions that are valid psychologically

Historically, the preformism of Weist et al. and their major theoretical influence (Smith 1980) comes from an acceptance of the pronouncements of linguistic investigation. Actually, in th generally quoted linguistic works in this area, such as Comrie (1976), there is no linguistic theory concerning a universal vocabulary of tense and aspect; there is only the comparative linguist's sense of deja vu. This sense of deja $v u$ carries the linguist into speculations concerning categories such as stative and dynamic, but does not provide a universal basis for the semantic analysis of predicates. As an illustration, let us consider the stative vs. dynamic distinction in English and Japanese.

The distinction in English surfaces as the co-occurrence of a dynamic predicate with the progressive, while in Japanese dynamic predicates co-occur with the continuative (Nakau 1976, 1980). While the two languages seem parallel in that similar classes exist in both languages, membership in one does not assure cross-translatability to a predicate of the comparable class in the other language. That is, a stative predicate in English need not be a stative predicate in Japanese. An excellent illustration is chosen by Weist et al. themselves, although indirectly, when they maintain that "be nervous" is a stative predicate (1984, p. 352). In English, it is stative in that we find it more comfortable to say "John is nervous" than "John is being nervous." 
In Japanese, however, the latter is exactly what you do say: John wa kinchoo shite iru 'John is being nervous' is a dynamic predicate that takes the continuative to refer to a state in effect at the time of speech. Many examples of this type exist, where English seems to prefer a stative and Japanese a dynamic expression: "bikkuri shite iru" 'is being surprised' (i.e., is surprised), "ai shite iru" 'is loving' (i.e., loves), and all have the, dynamic morphology of the continuative inflection. The reason for this situation is historical accident. Historical events of borrowing and adoption have allowed the morphology of these predicates to take shape. The moral here is that morphological distinctions, however distinct in the adult mind, may not directly reflect cognitive categories.

The problem becomes acute when Weist et al. try to formulate primitive aspectual distinctions. They propose that children view events internally and externally. The features incomplete, durative, and continuous comprise the internal category, while the features complete, punctual and discontinuous comprise the external category (Weist et al. 1984, p. 370). At first these might seem to be mutually exclusive sets of features, but a counter-example is found in Japanese, where continuativity can be shared by both durative and punctual actions. In Japanese, continuativity is signalled by an affix string -te $i-$, while durativity and punctuality are lexical features. When durative verbs such as "nom-" 'drink' are continuative, the incomplete substage of the event is signified, "nonde iru" 'is drinking'. When punctual verbs such as "hair-" 'enter' are continuative, the result substage of the event is signified, "haitte iru" 'has entered, is inside'. In Japanese, the feature continuative, which is internal according to Weist et al., can be coupled with the feature punctual, which is external according to Weist et al. This arrangement causes Japanese children absolutely no problem. From as early as 22 months the same inflection is used to signify both continuing incomplete aspects and continuing complete aspects of events (Rispoli, 1983). Japanese children use the same inflection to signal internal and external perspectives. 
To summarize, Weist et al. have attempted to adopt linguistic theory as psychological theory. The problem with such an attempt is that there is no real linguistic theory to begin with. Even the most primitive of aspectual oppositions has its exceptions. Further, to say that a predicate is stative or dynamic in one language does not inform us about its aspectual characteristics in another language. In short, there is no real universal in the semantic structure of verb-like and adjective-like predicates. Perhaps we would be more comfortable if we were studying syntax, where rule schemas and not predicates comprise our universals, but tense and aspect are semantic domains, and universal statements about tense and aspect must be universal statements about meaning. Without universals we have no reason to adopt a linguistic analysis for psychological theory. This leaves us with only one real alternative, which is to attempt, as Bloom et al. did, to characterize child language data in terms of the categories derived from the child's language behavior. We are forced to search in the contextual events which relate to the child's utterance for cues to the motivating categories and distinctions which comprise the child's knowledge in this domain.

\section{References}

Bloom, L., Lifter, K. \& Hafitz, J. (1980). Semantics of verbs and the development of verb inflection in child language. Language, 56. pp. 386-412.

Bronckart, J. P. \& Sinclair, H. (1973). Time, tense and aspect. Cognition, 2. pp. 107-30.

Comrie, B. (1976). Aspect: An introduction to the study of verbal aspect and related problems. Cambridge: Cambridge University Press.

Nakau, M. (1976). Tense, aspect and modality. In M. Shibatani (Ed.), Japanese generative grammar: Syntax and semantics 5. New York: Academic Press.

Nakua, M. (1980). Tensu to asupekuto no hikaku. In T. Kunihiro (Ed.) Eigo hikaku kooza. Bunpoo 2. Tokyo: Taishukan.

Rispoli, M. (1983). Acquiring tense-aspect inflection in Japanese. Paper presented at the Harvard Conference on Japanese and Korean Linguistics.

Smith, C. S. (1980). The acquisition of time talk: relations between child and adult grammars. Journal of Child Language, 7. pp. 263-78.

Weist, R., Wysocka, H., Witkowska-Stadnik, K. Buczowska, E. \& Konieczna, E. (1984). The defective tense hypothesis: On the emergence of tense and aspect in child Polish. Journal of Child Language, 11, pp. 347-374. 